\title{
The Role of Universal Basic Income in Preventing and Ending Homelessness
}

\author{
Nick Kerman, $\mathrm{PhD}{ }^{1}$ \\ ${ }_{1}$ Centre for Addiction and Mental Health, \\ Toronto, Ontario, Canada \\ Correspondence \\ Author, Affiliation: Centre for Addiction and \\ Mental Health, \\ Toronto, Ontario, Canada, M6J 1H4. \\ Email: nick.kerman@camh.ca. \\ All content published in IJOH is licensed \\ under a Creative Commons Attribution- \\ NonCommercial-ShareAlike 4.0 \\ International license (CC BY-NC-SA 4.0). \\ Received: 16 Nov 2020 \\ Accepted: 12 Apr 2021
}

\begin{abstract}
There are growing calls for Universal Basic Income (UBI) as a means of reducing poverty and addressing the changing nature of work. UBI involves the provision of a cash payment to all adult citizens, which is sufficient to live on and either does not phase out as earnings increase or does so slowly for higher incomes. Despite many theorized benefits and beneficiaries of UBI, its implications for preventing and ending homelessness have not been explored. Accordingly, this commentary provides an overview on UBI and its evidence base, and then discusses how UBI could help to structurally prevent and end homelessness by reducing values-based exclusion in the provision of income supports, promoting choice in housing, facilitating workforce returns and buffering against automation job losses, and improving health and well-being. Like any transformative policy shift, there are also risks associated with UBI, which largely lie in the details of how it is designed and the political context in which it is implemented. Nevertheless, given its potential, now is the time to properly trial UBI as a structural intervention for preventing and ending homelessness.
\end{abstract}

\section{Keywords}

universal basic income; guaranteed annual income; homelessness; structural prevention; Housing First

\section{Introduction}

The origins of universal basic income (UBI), which is also commonly referred to as a guaranteed annual income, can be traced back centuries, but its prominence in public policy discourse increased during the 1960s and 1970s when several pilot experiments were conducted in Canada and the United States. More pilot projects have been conducted since then, but permanent adoption in public policy has yet to occur anywhere in the world. Despite UBI being relegated largely to the pilot stage, there has been considerable movement within the past five years. In 2016, Switzerland held a national referendum on adoption of UBI, which was rejected. Then, in late 2017, Andrew Yang announced his candidacy for president of the United States. The primary policy of his platform

\section{3 | International Journal on Homelessness: https:/ /ijoh.ca}


was the "Freedom Dividend," which would provide a UBI of $\$ 1,000$ USD per month to all American adults. It was during this time that UBI found its spotlight.

Along with UBI's prominent emergence in public discourse and magnified by the job losses during the COVID-19 pandemic, there has been an uptake in calls for its use as a strategy to reduce poverty. UBI has even found its way into ideological strategies for addressing homelessness. For example, the Canadian Alliance to End Homelessness' national campaign, Recovery For All, proposed a UBI to provide an adequate income that meets the costs of living and does not stigmatize or penalize people through rules and conditions (Canadian Alliance to End Homelessness, 2020). However, beyond this recent flurry of attention, the potential of UBI for preventing and ending homelessness has been under-examined. Accordingly, this commentary will provide an overview of UBI and its evidence base and discuss the implications of UBI for preventing and ending homelessness.

\section{What Is UBI?}

Although there is not consensus on what constitutes a UBI, Hoynes and Rothstein (2019) proposed three central features: (a) the provision of a cash payment that is sufficient to live on, without other earnings; (b) either no phaseout or a slow phaseout as earnings increase; and (c) cash payments are accessible to a large proportion of the population as opposed to a targeted subset (e.g., people with disabilities). The former feature is universal in the purest form of UBI, meaning that all adults would receive cash benefits regardless of family structure, income, age, disability status, and workforce involvement. Dependent children would also be provided a smaller cash payment, essentially a universal child allowance, as developmental outcomes are positively associated with family income (Bradley \& Corwyn, 2002; Reiss, 2013; Stephens, 2019). However, to manage costs associated with implementation, UBI proposals and pilots have sometimes limited eligibility based on income or other family characteristics (Hoynes \& Rothstein, 2019). Hence, the term "universal" requires critical examination in schemes described as UBI.

Considering the aforementioned central features proposed by Hoynes and Rothstein (2019),
UBI works by providing universal, flat-rate cash payments without any means testing (Van Parijs, 1991). Earnings from workforce involvement do not affect UBI cash payment rates, unless there is a phaseout for higher incomes at which point the UBI is scaled back (Hoynes \& Rothstein, 2019). There are two important implications to this UBI scheme. First, given its universality, low-income recipients are not expected to be subjected to the same judgment and stigma that is associated with existing income support programs in North America (Morley et al., 2019). Second, it addresses key poverty trap mechanisms. With UBI cash payments being sufficient to live on, people are not forced to accept low-wage jobs to make ends meet and can instead invest their time into other pursuits, such as child care or education, that could be potentially beneficial to future employment (Shåhl \& MacEachen, 2021). Further, unlike income support programs that claw back earned income from paid employment, UBI cash payments either do not phase out or only do so slowly at higher income levels. As such, UBI reduces the disincentive to returning to the workforce. Lastly, to access many existing disability income support programs in North America, people must commonly demonstrate an inability to work due to injury or illness (Shåhl \& MacEachen, 2021). Without means testing, UBI does not involve determinations about whether or not people are able to work, thereby changing the messaging to people with disabilities and providing them the freedom to work if they are able or engage in rehabilitative treatments that may help them return to the workforce.

A variant of guaranteed annual income is the negative income tax (NIT). Although it has the potential to achieve the same intended goals as UBI, the NIT operates with a different philosophical stance (Stephens, 2019). As proposed by Milton Friedman in 1962, the NIT would incentivize labor force participation for people receiving income support benefits by increasing their net income from paid work (Moffitt, 2003). The NIT would theoretically achieve this goal by negatively taxing individuals under a certain income threshold (i.e., people with low incomes would receive money back from the government similar to a tax credit). For example, using a 50\% negative tax rate and an income threshold of $\$ 20,000$, a person with no income would receive $\$ 10,000$, whereas someone making $\$ 10,000$ from paid work would receive an 
additional $\$ 5,000$ from a NIT. If income were to exceed $\$ 20,000$, taxes are only paid on the amount above the threshold. Thus, unlike UBI where flat cash payments are provided to all citizens, the income from NIT schemes vary based on earnings.

\section{What Is the Evidence for UBI?}

The UBI evidence base is primarily comprised of pilot NIT experiments and studies of dividend payment distributions; the latter involves dividends from community resources being shared with a broader community (e.g., oil resources in Alaska, casinos on Indigenous lands across North America; Gibson et al., 2020). Although all of these programs involved unconditional payments, many were neither universal nor permanent (Gibson et al., 2020). Despite not having all of the central features of UBI (Hoynes \& Rothstein, 2019), the research findings offer important evidence on the potential of guaranteed annual income. A scoping review by Gibson et al. (2020) found that UBI-type interventions were linked to positive health outcomes, particularly among children and disadvantaged groups, and decreases in offending and substance use-related crimes. Improvements in mental health outcomes were believed to be attributable to reduced stress related to finances. Further, contrary to the common critique that UBI will lead to substantial reductions in workforce participation, NIT experiments had mostly nonsignificant impacts on the number of hours worked per year, though reductions were greater among women, particularly those with young children. This effect was due to their involvement in other activities, including education and caring for dependents. A recent pilot UBI experiment in Finland yielded similar findings (Kangas et al., 2020). A total of 2,000 adults received an unconditional monthly payment of $€ 560$ from 2017 2018, and this UBI was not associated with reductions in employment. Further, compared to the general population, UBI recipients reported lower levels of stress and depressive symptoms, and better cognitive functioning and financial wellbeing during the study period.

There is a dearth of research on the effects of UBI on housing outcomes. A recent survey of over 400 enrollees in the NIT pilot in Ontario, Canada, found that $58.5 \%$ reported improvements in their housing situations as a result of the program (Basic Income Canada Network, 2019). The perceived improvements in housing stability are likely the result of NIT incomes being considerably higher than pre-existing income support program rates, allowing people to more effectively balance housing safety and affordability (Hamilton \& Mulvale, 2019). Further, people reported that they were not forced to choose between rent and food, which is an indicator of housing transitions and homelessness risk (Czechowski et al., under review). Although these studies did not examine housing changes over time, they offer an important perspective, albeit a preliminary one, on how NIT or UBI cash payments can be used to stabilize housing and address related quality of life needs.

Preliminary findings from a recent Canadian pilot experiment, New Leaf project, which provided a one-time cash payment of $\$ 7,500$ CAD approximately $\$ 6,000$ USD - to people experiencing homelessness (Foundations for Social Change, 2020), highlights the potential of UBI for this population. The cash transfer amount was benchmarked against the regional annual income support rate to examine whether or not a larger, single payment would be more transformative than smaller, monthly ones. It must be noted that the studied intervention differs from UBI in that it did not provide ongoing funds, only the single cash transfer; however, this amount is higher than many UBI and NIT proposals and pilots. One-year findings showed that payment recipients exited homelessness quicker, spent fewer days homeless, and experienced improved food security than participants who did not receive cash payments (Foundations for Social Change, 2020). Moreover, the costs of the payments were offset by the reduced use of emergency shelters over the 12-month period. Overall, the study demonstrates how direct cash payments that make the rental housing market more immediately accessible might be a springboard out of homelessness.

\section{How Could UBI Help to Prevent and End Homelessness?}

Using a homelessness prevention framework (Dej et al., 2020; Oudshoorn et al., 2020), UBI would constitute structural prevention through its alteration of legislation and policy that promotes primordial stabilization and tertiary intervention. The former focuses on policy-level preconditions of social issues, such as financial security, whereas the latter involves mitigation of the harmful effects of 
existing problems, or homelessness in this case (Oudshoorn et al., 2020). Operating on the assumption that UBI would provide a level of income that is sufficient for meeting all physiological needs, there are four mechanisms for how UBI could help to structurally prevent and end homelessness: (a) reducing values-based exclusion in the provision of income supports, (b) promoting choice in housing, (c) facilitating workforce returns and buffering against automation job losses, and (d) improving health and well-being.

\section{Reducing values-based exclusion in the provision of income supports}

Most existing income support programs in North America function on the basis of means testing. That is, people must meet eligibility criteria, whether it be having an income and assets below a designated threshold, having a verifiable and accepted disability, having a sufficient history of involvement in the workforce, agreeing to actively look for a job and returning to the workforce, or another requirement. Means testing produces categorization of people with deleterious consequences; a person in need is either deserving or undeserving (Moffitt, 2015). People who do not meet the values-based criteria of income support programs are excluded (Lowrey, 2018). People who are not disabled enough, are not poor enough, are not old enough, are not able to work enough, or have not previously worked enough are deemed not deserving enough and are left to fend for themselves. Rejection or termination of income support can precipitate and perpetuate homelessness (Wallace et al., 2006; Zlotnick et al., 1999).

As a universal cash payment, UBI would do away with means testing, preventing the exclusion of people based on neoliberal values. UBI would provide a buffer against homelessness by ensuring that people have a stable source of income that is not affected by one's able-bodiedness or labor market noninvolvement, nor would it be terminated due to changes in life circumstances (e.g., acquisition of a job, improvement in an episodic mental illness). Further, some existing income support programs in North America have allowances for housing and shelter costs. If people do not have housing and shelter costs, which is often but not always the case in the context of homelessness, they do not receive the allowance - another form of means testing. By providing cash payments that do not fluctuate as a result of housing status, UBI would enable people experiencing homelessness to save the money that would have been allocated to paying rent or living costs. Like the New Leaf project that provided a large, lump sum cash payment to people experiencing homelessness (Foundations for Social Change, 2020), accumulated UBI income during homelessness could help people to afford a rent deposit (e.g., first and last month's rent) and expedite exits out of homelessness.

\section{Promoting choice in housing}

A fundamental part of the experience of homelessness is a lack of choice and control; people's freedom over where they live, what and when they eat, and where they go each day is limited (Kerman \& Sylvestre, 2020; Nicholls, 2010). As people look for housing, their options are often restricted by their low incomes, further perpetuating their homelessness or forcing them to accept inadequate or unsafe housing that does not meet their needs (Fisher et al., 2014; Tischler, 2008). By providing cash payments that are sufficient to live on (i.e., payments would be greater than existing income support program rates) and are not scaled back during episodes of homelessness, UBI could offer a pathway out of homelessness by promoting more housing choice and control. Instead of people feeling that they need to accept the first available housing option out of desperation, the increased funds could provide people with several options from which to choose, including not only subsidized units but also affordable market rent housing. Past research has shown a positive relationship between housing choice and stability, albeit a weak association that may be time limited (Srebnik et al., 1995; Tsai \& Rosenheck, 2012). A sense of control in housing has also been linked to an increased likelihood of housing sustainment (Boland et al., 2018). Accordingly, there is a continued need to prioritize interventions that promote housing choice and control for people experiencing homelessness, or have that potential, as is the case with UBI.

Another way that UBI may foster housing choice is by reducing landlords' discrimination against people experiencing homelessness. For example, in the U.S., landlords have been found to discriminate against individuals who hold housing 
choice vouchers, despite this group causing no more problems than tenants without vouchers (Tighe et al., 2017). Income source-based discrimination in housing could be prevented by the universality of UBI, as all prospective tenants have a common income source. It is important to note that many people experiencing homelessness encounter multiple forms of housing discrimination (e.g., related to race and ethnicity, gender identity and sexual orientation, family composition, unemployment, history of involvement in the criminal justice system; Ecker et al., 2019; Paul et al., 2020; Walsh et al., 2016) that extend beyond income source and for which UBI may have less of an effect. Accordingly, on its own, the impacts of UBI on housing discrimination are more likely to be incremental than transformative.

UBI's promotion of housing choice and control would also augment existing evidence-based interventions for addressing chronic homelessness, such as Housing First. Housing First involves the provision of housing subsidies with ongoing supports to facilitate immediate access to housing (Padgett et al., 2016). Housing First tenants have choice and control over their housing and supports, including whether or not to access available services. The intervention has been shown to be highly effective in stably housing people experiencing chronic homelessness (Aubry et al., 2020; Stergiopoulos et al., 2019). However, obtaining housing in communities with low vacancy rates can be a prominent challenge (Nelson et al., 2014). The combination of UBI payments with a Housing First rent subsidy could help to overcome this barrier, as people experiencing homelessness would have more funds that could be allocated to housing costs. Further, if UBI provides Housing First tenants with more money in their pockets, this could be an asset to strengthening their community and neighbourhood ties. Community integration has been a challenge for Housing First (Marshall et al., 2020). This is partially due to Housing First tenants being unable to afford entertainment and leisure activities (Bassi et al., 2020; Kerman \& Sylvestre, 2020). However, in a study that provided an additional $\$ 73$ USD per month to people with serious mental illness, the funds were used in different ways; some participants spent the money on hobbies and personal pleasures, whereas others used the funds for social connection and interaction (Topor \& Ljungqvist, 2017). As such, extra funds from UBI could be used similarly to further community integration and connection among Housing First tenants. Overall, the combination of the evidencebased Housing First approach, investments to build new affordable housing, and a UBI could be a powerful force in efforts to end homelessness and enable people to live meaningful lives in their communities.

\section{Facilitating workforce returns and buffering against automation job losses}

Like housing, choice in employment is limited for people experiencing or at-risk of homelessness. There are various reasons for this, including limited time to address competing unmet needs (e.g., shelter, food, child care, employment, healthcare, and so on), fewer opportunities due to lower education attainment, and existing income support programs' restrictive policies on employment. As previously noted, the latter issue can take different forms, from requiring those living with a disability to demonstrate an inability to work to qualify for funding, putting a cap on earned income after which point income supports may be terminated, or clawing back earnings from employment (Morley et al., 2019; Shåhl \& MacEachen, 2021). Each of these policies disincentivize workforce returns, which may be the difference between housing and homelessness for people who are just scraping by on their income supports. UBI would bring an end to this systemic problem, as cash payments are unconditional, with no work or nonwork requirements. If a UBI were to have a phaseout (i.e., the point at which UBI cash payments are scaled back), this would not affect people with low incomes, as it would only take effect at a much higher income threshold. Hence, UBI would foster self-determination by removing barriers to returning to the workforce for people experiencing or at-risk of homelessness.

The second employment-related benefit of UBI is its implications for workplace automation. UBI is often discussed as a policy approach for reducing the harms to job and income security associated with increasing automation (Morley et al., 2019). There are no known studies examining the relationship between homelessness and workforce automation; however, the risks are evident. In a study of OECD countries, risk of job automation was negatively correlated with workers' income and level of education (Arntz et al., 2016). As low 
education and income levels are both overrepresented in the homeless population (Hwang et al., 2011; Poremski et al., 2015), it would be surmisable that the vocational prospects of many people with histories of homelessness are at higher risk of automation. A recent study by Tsai et al. (2021) of automation in another group vulnerable to homelessness drew a similar conclusion. A survey of vocational rehabilitation programs for veterans in the U.S. showed that the most common job placements had the highest probability of being automated (Tsai et al., 2021). Although more research is needed on the effects of workforce automation on homelessness, UBI could serve as a crucial buffer against future job losses that exacerbate or perpetuate homelessness risks.

\section{Improving mental health and well-being}

Mental health problems can play a prominent role in many pathways into homelessness. Substance use problems, psychosis, mood and anxiety disorders, trauma symptoms, and personality disorders are each independently associated with increased risk of becoming homeless (Nilsson et al., 2019). High rent burden, which refers to spending a greater percentage of one's income on housing costs, can also produce chronic stress (Padgett, 2020) that increases vulnerability for developing or exacerbating mental illness or substance use problems (Brady \& Sinha, 2005). Accordingly, improving mental health and well-being has implications for preventing homelessness. Income is a key social determinant of mental health (Allen et al., 2014; Sareen et al., 2011). As found in the scoping review by Gibson et al. (2020) and Finnish pilot experiment (Kangas et al., 2020), UBI and NIT schemes had positive, interconnected effects on mental health and financial well-being. The financial security generated by a guaranteed livable income may not only improve the mental health of people with low incomes and high rent burdens but also those with serious mental illness who face an increased risk of homelessness.

UBI may also have unique implications for preventing family homelessness. Many families experiencing homelessness are female-headed with young children who become homeless due primarily to financial instability (Grant et al., 2013; Sylvestre et al., 2018). The unaffordability of child care can keep low-income women out of the workforce and without the income needed to sustain their tenancies (Gulliver-Garcia, 2016; Polillo \& Sylvestre, 2021; Rabiah-Mohammed et al., 2020). Mothers of young children in the NIT experiments reviewed by Gibson et al. (2020) were found to have reductions in workforce involvement. The authors theorized that this was due to mothers using the cash payments as de facto paid maternity leave, which was often unavailable to women in the studies. As paid maternity leave is linked to better maternal mental health (Aitken et al., 2015), UBI has the potential to concurrently strengthen the housing stability and mental health of families at-risk of homelessness by providing sufficient income to engage in instrumental, unpaid work activities, such as child care.

\section{What are the Risks of UBI to Efforts to Prevent and End Homelessness?}

A transformative change in policy that affects numerous sectors and services, such as UBI, inevitably carries risks. The most serious concern is the extent to which other services that comprise social safety nets, which are complementary but not duplicative of UBI, are defunded. Implementation of UBI would replace some existing services, such as income support programs, but there is risk that other publicly funded health and social services would also be defunded. As noted by Raphael et al. (2019), it is important to recognize the neoliberal context in which a UBI would be implemented and how this could lead to such a policy being shaped to meet corporate interests and used to cut social services. This risk will be inherently present should UBI be designed and implemented in capitalistic economies, raising the need for caution, though there are considerations for risk mitigation. UBI must not be framed as a poverty reduction panacea, nor it is one for preventing and ending homelessness. Although UBI has the potential to reduce homelessness rates, it will not produce needed changes on other, ongoing crises that afflict large proportions of this population, such as the overdose crisis, inequitable access to mental health services, or the lack of investments to build new affordable housing. As such, advocacy on homelessness neither starts nor ends with UBI and the goal must be to develop a menu of systems- and individual-level interventions to address homelessness, one of which may be a guaranteed annual income. Another risk mitigation strategy 
would be to test the cost-effectiveness of UBI in controlled experiments. Being able to make a compelling moral and economic case for UBI as a strategy for addressing homelessness may create fiscal space to protect other health and social services against austerity measures. Nevertheless, the erosion of other components of the social safety net following UBI implementation remains an uncertain risk to efforts to prevent and end homelessness.

A related risk is that UBI will result in a pivot away from existing best practices to addressing homelessness, like permanent supportive housing, particularly the Housing First approach (Pottie et al., 2020). This risk may be exacerbated by the universality of UBI, which could be perceived as a one-size-fits-all response to poverty reduction and homelessness. However, the homeless population is heterogenous, with diverse support needs that vary in intensity. Accordingly, a range of interventions are needed to support people experiencing homelessness and there is room for both existing best practices and UBI in efforts to end homelessness. Further, UBI may augment efforts to end chronic homelessness using a Housing First approach, but it cannot be implemented as its successor or replacement. Investments in and prioritization of the Housing First approach must continue. UBI only stands to have a positive impact on preventing and ending homelessness if favorable approaches are not rid of with the unfavorable.

A third risk consideration is how UBI would work for youth experiencing homelessness who are under 18 years of age. UBI is typically discussed as a cash payment to adults, with a smaller cash payment being provided to dependent children (Stephens, 2019). However, youth experiencing homelessness are not "dependent children" in the traditional sense. They may rely on community services for shelter, food, and care, but they are active agents in their own lives - making decisions independently, or interdependently with others, about how they will meet their basic needs. As youth and adults experiencing homelessness have the same fundamental unmet need - housing - UBI could fulfill the same role of helping both groups to exit homelessness. The utility of direct cash transfers has been explored for youth experiencing homelessness. Preliminary research by Morton et al. (2020) found that such a scheme could potentially have a transformative effect on youth homelessness, but payment amounts need to be sufficient to obtain housing in local markets and be provided for one year or longer to facilitate stability. Accordingly, making cash payments available to youth experiencing homelessness via UBI may also help this group exit homelessness.

Overall, adoption of UBI as a structural intervention for preventing and ending homelessness carries risks that are contingent on what other policy changes are implemented alongside or following it. Although UBI may replace some services (e.g., existing income support programs), it must not lead to the erosion of other community programs that are instrumental in meeting the basic needs of people experiencing homelessness. Nor must UBI result in a departure from evidence-based practices, such as Housing First, or investments in new affordable housing. Accordingly, the effectiveness of UBI in preventing and ending homelessness would be a case of the devil is in the details. If cash payment rates are insufficient to live on, its potential for addressing homelessness will be undermined. Further, its eligibility for youth experiencing homelessness requires careful consideration and advocacy to ensure that these groups are not left out.

\section{Conclusions}

The evidence for UBI is limited but promising. With regard to housing outcomes, there is no definitive evidence that a UBI will prevent and end homelessness. However, there is ample evidence demonstrating that current social policies, including existing income support programs, are largely inadequate for preventing and ending homelessness. Further, there is reason to speculate that a UBI could address homelessness by reducing values-based exclusion in the provision of income supports, promoting choice in housing, facilitating workforce returns and buffering against automation job losses, and improving health and well-being. Such a transformative policy shift also carries risks, which lie in the details of how a UBI is designed and implemented. At least some of these risks can be anticipated and addressed through planning, testing, and advocacy. Given its potential, now is the time to properly trial UBI in diverse communities using experiments that are adequately powered and extend over several years. In short, it is too early to say that UBI will be effective in 
preventing and ending homelessness, but we are overdue to rigorously study it.

\section{References}

Aitken, Z., Garrett, C. C., Hewitt, B., Keogh, L., Hocking, J. S., \& Kavanagh, A. M. (2015). The maternal health outcomes of paid maternity leave: A systematic review. Social Science \& Medicine, 130, 32-41.

doi:10.1016/j.socscimed.2015.02.001

Allen, J., Balfour, R., Bell, R., \& Marmot, M. (2014). Social determinants of mental health. International Review of Psychiatry, 26(4), 392407.

https://doi.org/10.3109/09540261.2014.92827 0

Arntz, M., Gregory, T., \& Zierahn, U. (2016). The risk of automation for jobs in OECD countries: A comparative analysis (OECD Social, Employment and Migration Working Papers, No. 189). OECD Publishing. https:// doi.org/10.1787/5jlz9h56dvq7-en

Aubry, T., Bloch, G., Brcic, V., Saad, A., Magwood, O., Abdalla, T., Alkateeb, Q., Xie, E., Mathew, C., Hannigan, T., Costello, C., Thavorn, K., Stergiopoulos, V., Tugwell, P., \& Pottie, K. (2020). Effectiveness of permanent supportive housing and income assistance interventions for homeless individuals in high-income countries: A systematic review. Lancet Public Health, 5(6), 342-360. https://doi.org/10.1016/S2468-2667(20)300554

Basic Income Canada Network. (2019). Signposts to success: Report of a BICN survey of Ontario basic income recipients. Basic Income Canada Network \& Ontario Basic Income Network. https://www.basicincomecanada.org/

Bassi, A., Sylvestre, J., \& Kerman, N. (2020). Finding home: Community integration experiences of formerly homeless women with problematic substance use in housing first. Journal of Community Psychology, 48(7), 23752390. https://doi.org/10.1002/jcop.22423

Boland, L., Slade, A., Yarwood, R., \& Bannigan, K. (2018). Determinants of tenancy sustainment following homelessness: A systematic review. American Journal of Public Health, 108, e1-e8. https://doi.org/10.2105/ajph.2018.304652

Bradley, R. H., \& Corwyn, R. F. (2002). Socioeconomic status and child development.
Annual Review of Psychology, 53, 371-399. https://doi.org/10.1146/annurev.psych.53.10 0901.135233

Brady, K. T., \& Sinha, R. (2005). Co-occurring mental and substance use disorders: The neurobiological effects of chronic stress. American Journal of Psychiatry, 162(8), 14831493.

https://doi.org/10.1176/appi.ajp.162.8.1483

Canadian Alliance to End Homelessness. (2020). Six point plan to end homelessness in Canada. https://www.recoveryforall.ca/

Czechowski, K., Sylvestre, J., Gogosis, E., Agha, A., Kerman, N., Polillo, A., Palepu, A., \& Hwang, S. W. (under review). Cycles of instability: Proximal and distal influences on residential instability in three Canadian cities.

Dej, E., Gaetz, S., \& Schwan, K. (2020). Turning off the tap: A typology for homelessness prevention. Journal of Primary Prevention, 41, 397-412. https://doi.org/10.1007/s10935-02000607-y

Ecker, J., Aubry, T., \& Sylvestre, J. (2019). A review of the literature on LGBTQ adults who experience homelessness. Journal of Homosexuality, 66(3), 297-323. https://doi.org/10.1080/00918369.2017.14132 77

Fisher, B. W., Mayberry, L. S., Shinn, M., \& Khadduri, J. (2014). Leaving homelessness behind: Housing decisions among families exiting shelter. Housing Policy Debate, 24(2), 364-386. https://doi.org/10.1080/10511482.2013.85260 3

Foundations for Social Change. (2020). Foundations for social change: New Leaf project. https:// forsocialchange.org/

Gibson, M., Hearty, W., \& Craig, P. (2020). The public health effects of interventions similar to basic income: A scoping review. Lancet Public Health, 5(3), e165-e176. https://doi.org/10.1016/S2468-2667(20)300050

Grant, R., Gracy, D., Goldsmith, G., Shapiro, A., \& Redlener, I. E. (2013). Twenty-five years of child and family homelessness: Where are we now? American Journal of Public Health, 103(S2), e1-e10. https://doi.org/10.2105/AJPH.2013.301618 
Gulliver-Garcia, T. (2016). Putting an end to child \& family homelessness in Canada. Raising the Roof. https:/ / www.raisingtheroof.org/

Hamilton, L., \& Mulvale, J. P. (2019). “Human again": The (unrealized) promise of basic income in Ontario. Journal of Poverty, 23(7), 576-599.

https://doi.org/10.1080/10875549.2019.16162 42

Hoynes, H., \& Rothstein, J. (2019). Universal basic income in the United States and advanced countries. Annual Review of Economics, 11, 929-958. https://doi.org/10.1146/annureveconomics-080218-030237

Hwang, S. W., Aubry, T., Palepu, A., Farrell, S., Nisenbaum, R., Hubley, A. M., Klodawsky, F., Gogosis, E., Hay, E., Pidlubny, S., Dowbor, T., \& Chambers, C. (2011). The health and housing in transition study: A longitudinal study of the health of homeless and vulnerably housed adults in three Canadian cities. International Journal of Public Health, 56, 609623. https://doi.org/10.1007/s00038-011-02833

Kangas, O., Jauhiainen, S., Simanainen, M., \& Ylikännö, M. (2020). Evaluation of the Finnish basic income experiment. The Ministry of Social Affairs and Health. http:/ / urn.fi/URN:ISBN:978-952-00-9890-2

Kerman, N., \& Sylvestre, J. (2020). Surviving versus living life: Capabilities and service use among adults with mental health problems and histories of homelessness. Health and Social Care in the Community, 28(2), 414-422. https://doi.org/10.1111/hsc.12873

Lowrey, A. (2018). Give people money: How a universal basic income would end poverty, revolutionize work, and remake the world. Crown.

Marshall, C. A., Boland, L., Westover, L. A., Marcellus, B., Weil, S., \& Wickett, S. (2020). Effectiveness of interventions targeting community integration among individuals with lived experiences of homelessness: A systematic review. Health and Social Care in the Community, 28(6), 1843-1962. https://doi.org/10.1111/hsc.13030

Moffitt, R. A. (2003). The negative income tax and the evolution of U.S. welfare policy. Journal of Economic Perspectives, 17(3), 119-140. https://doi.org/10.1257/089533003769204380
Moffitt, R. A. (2015). The deserving poor, the family, and the U.S. welfare system.

Demography, 52(3), 729-749. https://doi.org/10.1007/s13524-015-0395-0

Morley, C., Ablett, P., \& Mays, J. (2019). A universal basic income: What difference might it make? Social Alternatives, 38(2), 11-18.

Morton, M. H., Chávez, R., Kull, M. A., Carreon, E. D, Bishop, J., Daferede, S., Wood, E., Cohen, L., \& Barreyro, P. (2020). Developing a direct cash transfer program for youth experiencing homelessness: Results of a mixed methods, multi-stakeholder design process. Chapin Hall at the University of Chicago. https://www.chapinhall.org/

Nelson, G., Stefancic, A., Rae, J., Townley, G., Tsemberis, S., Macnaughton, E., Aubry, T., Distasio, J., Hurtubise, R., Patterson, M., Stergiopoulos, V., Piat, M., \& Goering, P. (2014). Early implementation evaluation of a multi-site housing first intervention for homeless people with mental illness: A mixed methods approach. Evaluation and Program Planning, 43, 16-26. https://doi.org/10.1016/j.evalprogplan.2013.1 0.004

Nicholls, C. M. (2010). Housing, homelessness and capabilities. Housing, Theory and Society, 27(1), 23-41. https:/ / doi:10.1080/14036090902764588

Nilsson, S. F., Nordentoft, M., \& Hjorthøj, C. (2019). Individual-level predictors for becoming homeless and exiting homelessness: A systematic review and meta-analysis. Journal of Urban Health, 96, 741-750. https://doi.org/10.1007/s11524-019-00377-x

Oudshoorn, A., Dej, E., Parsons, C., \& Gaetz, S. (2020). Evolving an evidence-based model for homelessness prevention. Health and Social Care in the Community, 28(5), 1754-1763. https:// doi.org/10.1111/hsc.13000

Padgett, D. K. (2020). Homelessness, housing instability and mental health: Making the connections. BJPsych Bulletin, 44(5), 197-201. https://doi.org/10.1192/bjb.2020.49

Padgett, D. K., Henwood, B. F., \& Tsemberis, S. J. (2016). Housing first: Ending homelessness, transforming systems, and changing lives. Oxford University Press.

Paul, D. W., Knight, K. R., Olsen, P., Weeks, J., Yen, I. H., \& Kushel, M. B. (2020). Racial discrimination in the life course of older adults 
experiencing homelessness: Results from the HOPE HOME study. Journal of Social Distress and Homelessness, 29(2), 184-193. https://doi.org/10.1080/10530789.2019.17022 48

Polillo, A., \& Sylvestre, J. (2021). An exploratory study of the pathways into homelessness among of foreign-born and Canadian-born families: A timeline mapping approach. Journal of Social Distress and Homelessness, 30(1), 6-19.

https://doi.org/10.1080/10530789.2019.17055 18

Poremski, D., Distasio, J., Hwang, S. W., \& Latimer, E. (2015). Employment and income of people who experience mental illness and homelessness in a large Canadian sample. Canadian Journal of Psychiatry, 60(9), 379-385 https:// doi.org/10.1177/070674371506000902

Pottie, K., Kendall, C. E., Aubry, T., Magwood, O., Andermann, A., Salvalaggio, G., Ponka, D., Bloch, G., Brcic, V., Agbata, E., Thavorn, K., Hannigan, T., Bond, A., Crouse, S., Goel, R., Shoemaker, E., Wang, J. Z. J., Mott, S., Kaur, H., \& Tugwell, P. (2020). Clinical guideline for homeless and vulnerably housed people, and people with lived homelessness experience. CMAJ, 192(10), e240-e254. https://doi.org/10.1503/cmaj.190777

Rabiah-Mohammed, F., Oudshoorn, A., \& Forchuk, C. (2020). Gender and experiences of family homelessness. Journal of Social Distress and Homelessness, 29(2), 151-160. https://doi.org/10.1080/10530789.2019.16794 20

Raphael, D., Bryant, T., \& Mendly-Zambo, Z. (2019). Canada considers a basic income guarantee: Can it achieve health for all? Health Promotion International, 34(5), 1025-1031. https://doi.org/10.1093/heapro/day058

Reiss, F. (2013). Socioeconomic inequalities and mental health problems in children and adolescents: A systematic review. Social Science \& Medicine, 90, 24-31. https://doi.org/10.1016/j.socscimed.2013.04.0 26

Sareen, J., Afifi, T. O., McMillan, K. A., \& Asmundson, G. J. G. (2011). Relationship between household income and mental disorders: Findings from a population-based longitudinal study. Archives of General Psychiatry, 68(4), 419-427. https://doi.org/10.1001/archgenpsychiatry.20 11.15

Shåhl, C., \& MacEachen, E. (2021). Universal basic income as a policy response to COVID-19 and precarious employment: Potential impacts on rehabilitation and return-to-work. Journal of Occupational Rehabilitation, 31, 3-6. https://doi.org/10.1007/s10926-020-09923-w

Srebnik, D., Livingston, J., Gordon, L., \& King, D. (1995). Housing choice and community success for individuals with serious and persistent mental illness. Community Mental Health Journal, 31, 139-152. https://doi.org/10.1007/BF02188763

Stephens, R. (2019). The universal basic income: Should it replace the existing social security system? Policy Quarterly, 15(1), 30-37. https://doi.org/10.26686/pq.v15i1.5293

Stergiopoulos, V., Mejia-Lancheros, C., Nisenbaum, R., Wang, R., Lahcaud, J., O'Campo, P., \& Hwang, S. W. (2019). Longterm effects of rent supplements and mental health support services on housing and health outcomes of homeless adults with mental illness: Extension study of the at home/chez soi randomized controlled trial. Lancet Psychiatry, 6(11), 915-925. https://doi.org/10.1016/S2215-0366(19)303712

Sylvestre, J., Kerman, N., Polillo, A., Lee, C. M., Aubry, T., \& Czechowski, K. (2018). A qualitative study of the pathways into and impacts of family homelessness. Journal of Family Issues, 39(8), 2265-2285. https://doi.org/10.1177/0192513×17746709

Tighe, J. R., Hatch, M. E., \& Mead, J. (2017). Source of income discrimination and fair housing policy. Journal of Planning Literature, 32(1), 315. https://doi.org/10.1177/0885412216670603

Tischler, V. (2008). Resettlement and reintegration: Single mothers' reflections after homelessness. Community, Work \& Family, 11(3), 243-252. https:/ / doi.org/10.1080/13668800802133628

Topor, A., \& Ljungqvist, I. (2017). Money, social relationships and the sense of self: The consequences of an improved financial situation for persons suffering from serious mental illness. Community Mental Health Journal, 53, 823-831. https://doi.org/10.1007/s10597-017-0146-3 
Tsai, J., Mehta, K., \& Elbogen, E. (2021). The potential impact of job automation on veterans in vocational rehabilitation programs. Psychiatric Services, 72(3), 329-332. https://doi.org/10.1176/appi.ps.202000172

Tsai, J., \& Rosenheck, R. A. (2012). Consumer choice over living environment, case management, and mental health treatment in supported housing and its relation to outcomes. Journal of Health Care for the Poor and Underserved, 23(4), 1671-1677. https:// doi.org/10.1353/hpu.2012.0180

Van Parijs, P. (1991). Why surfers should be fed: The liberal case for an unconditional basic income. Philosophy \& Public Affairs, 20(2), 101-131.

https.//www.jstor.org/stable/2265291

Wallace, B., Klein, S., \& Reitsma-Street, M. (2006).

Denied assistance: Closing the front door on welfare in BC. Vancouver Island Public Interest Research Group \& Canadian Centre for Policy Alternatives. https://www.policyalternatives.ca/

Walsh, C. A., Hanley, J., Ives, N., \& Hordyk, S. R. (2016). Exploring the experiences of newcomer women with insecure housing in Montréal Canada. Journal of International Migration and Integration, 17, 887-904. https://doi.org/10.1007/s12134-015-0444-y Zlotnick, C., Robertson, M. J., \& Lahiff, M. (1999). Getting off the streets: Economic resources and residential exits from homelessness. Journal of Community Psychology, 27(2), 209-224. https://doi.org/10.1002/(SICI)15206629(199903)27:2<209::AID-JCOP8>3.0.CO;2-2 